\title{
OPERATIONAL RETRIEVAL OF AEROSOL OPTICAL DEPTH OVER INDIAN SUBCONTINENT AND INDIAN OCEAN USING INSAT-3D/IMAGER AND PRODUCT VALIDATION
}

\author{
Manoj K Mishra ${ }^{\text {, }}$ Gunjan Rastogi ${ }^{\text {a }}$, Prakash Chauhan ${ }^{\text {a,** }}$ \\ a Space Applications Centre, Indian Space Research Organisation, \\ Ahmedabad, India \\ *prakash@sac.isro.gov.in
}

KEY WORDS: Aerosols, geostationary satellite, optical depth, INSAT 3D, MODIS

\begin{abstract}
:
Aerosol optical depth (AOD) over Indian subcontinent and Indian Ocean region is derived operationally for the first time from the geostationary earth orbit (GEO) satellite INSAT-3D Imager data at $0.65 \mu \mathrm{m}$ wavelength. Single visible channel algorithm based on clear sky composites gives larger retrieval error in AOD than other multiple channel algorithms due to errors in estimating surface reflectance and atmospheric property. However, since MIR channel signal is insensitive to the presence of most aerosols, therefore in present study, AOD retrieval algorithm employs both visible (centred at $0.65 \mu \mathrm{m}$ ) and mid-infrared (MIR) band (centred at $3.9 \mu \mathrm{m}$ ) measurements, and allows us to monitor transport of aerosols at higher temporal resolution. Comparisons made between INSAT-3D derived AOD $\left(\tau_{\mathrm{I}}\right)$ and MODIS derived AOD $\left(\tau_{\mathrm{M}}\right)$ co-located in space (at $1^{\circ}$ resolution) and time during January, February and March (JFM) 2014 encompasses 1165, 1052 and 900 pixels, respectively. Good agreement found between $\tau_{\mathrm{I}}$ and $\tau_{\mathrm{M}}$ during JFM 2014 with linear correlation coefficients (R) of 0.87, 0.81 and 0.76 , respectively. The extensive validation made during JFM 2014 encompasses 215 co-located AOD in space and time derived by INSAT 3D $\left(\tau_{\mathrm{I}}\right)$ and 10 sun-photometers $\left(\tau_{\mathrm{A}}\right)$ that includes 9 AERONET (Aerosol Robotic Network) and 1 handheld sun-photometer site. INSAT-3D derived AOD i.e. $\tau_{\mathrm{I}}$, is found within the retrieval errors of $\tau_{\mathrm{I}}=$ $\pm 0.07 \pm 0.15 \tau_{\mathrm{A}}$ with linear correlation coefficient (R) of 0.90 and root mean square error equal (RMSE) to 0.06. Present work shows that INSAT-3D aerosol products can be used quantitatively in many applications with caution for possible residual clouds, snow/ice, and water contamination.
\end{abstract}

\section{INTRODUCTION}

To date, the global distributions of aerosols have been obtained more extensively from low earth orbit (LEO) satellites, such as the moderate resolution imaging spectroradiometer (MODIS), multi-angle imaging spectroradiometer (MISR), visible infrared scanner (VIRS) or advanced very high resolution radiometer (AVHRR), using their sophisticated channel designs (Diner et al. 1996, Kaufman et al. 1997, Tanre et al. 1997, Higurashi and Nakajima 1999, Ignatov and Stowe 2000, von Hoyningen et al. 2003, Remer et al. 2005, Kim et al. 2007), compared to those from geostationary earth orbit (GEO) satellites (Knapp et al. 2002, Wang et al. 2003). Aerosol optical depth (AOD) retrievals utilizing LEO satellite data provides global distribution of aerosols at high spatial distribution but are limited in temporal resolution. It has been observed that although aerosols may not exhibit a systematic diurnal trend (Kaufman et. Al., 2000), but availability of continuous measurements of AOD could provide information on aerosol emissions and transport from strong sources (e.g., biomass burning, dust storms etc.). In contrast to the AOD retrieval using LEO satellites, the algorithm for GEO satellites enables us to monitor AOD at a higher temporal sampling rate. As the signal received at the satellite consists of contributions from surface, atmosphere and aerosols, the basic principle of AOD retrieval is to separate the contribution of aerosols from the total signal received at the satellite. Since contribution due to the Rayleigh scattering can be calculated with high certainty, therefore estimation of surface reflectance in advance is crucial and is the major source of errors in AOD retrieval. This limits the AOD retrieval over ocean or dark vegetation in land where the surface contribution can be neglected (Higurash and Nakajima 1999, 2002.

Currently available GEO satellites have limited number of spectral channels and for this reason the AOD algorithms developed for multi-channel sensors like MODIS, MISR, VIRS and AVHRR cannot be implemented with GEO satellite data. In recent past, clear sky composite method has been widely used for retrieval of AOD values utilizing data from limited number of channels from GEO satellite (Knapp et al., 2002; Wang et al., 2003; Yoon et al., 2007). The basic assumption for estimating surface reflectance in clear sky composite method is that at least one clear day can be found for every pixel and that the surface reflectance does not change over a period of 30 days in visible band. However, this assumption fails in numerous atmospheric as well as surface conditions which lead to flaws in estimated AOD values. Mid-infrared (MIR) spectral region is not sensitive to the presence of most aerosols (Kaufman and Remer 1994). Using these facts Kim et al. (2008) proposed the utilization of MIR channel to improve the estimation of surface reflectance and thereby leading to improved AOD retrievals.

The goal of this study is to demonstrate the viability of using data acquired from recently launched Indian metrological geostationary satellite, INSAT-3D for the development of aerosol retrieval algorithm over Indian subcontinent and Indian Ocean. INSAT-3D derived AOD values are validated at 10 different sun-photometer sites that include 9 AERONET (Aerosol Robotic Network) sites and 1 handheld Microtops-II sun-photometer at SAC (ISRO), Ahmedabad. Here, the surface reflectance is obtained using visible channel as well as MIR channel for a previous certain number of days. 6S (second simulation of the satellite signal in the solar spectrum) (Vermote 
et al. 1997) code is used for Radiative transfer simulation (RTS) to construct various look up tables (LUTs) required for estimating the Rayleigh scattering contribution to total signal at satellite level and for correction of clear-sky composites to estimate surface reflectance more accurately. Although the usage of the mid-IR channel is restricted over dark vegetation, this channel will assist in improving the accuracy in estimating surface reflectance and thus the accuracy of the AODs. The retrieval method is detailed in the next sections followed by an analysis of the retrieval uncertainty. The algorithm is then validated against ground observations and compared to satellite retrievals.

\section{DATA USED}

\subsection{INSAT 3D/Imager data}

In this study Level 1C data acquired during January to March 2014 (08:00 UTC) from INSAT-3D/Imager is used. INSAT-3D carries a multi-spectral imager (optical radiometer) that generates the images of the earth in six wavelength bands significant for meteorological observations. Specifications of INSAT-3D/Imager are summarized in the table-1.

\begin{tabular}{|l|c|c|}
\hline $\begin{array}{c}\text { INSAT-3D Imager } \\
\text { Bands }\end{array}$ & $\begin{array}{c}\text { Nominal } \\
\text { wavelength } \\
\text { range }(\mu \mathrm{m})\end{array}$ & $\begin{array}{c}\text { Resolution } \\
(\mathrm{km})\end{array}$ \\
\hline Visible & $0.55-0.75$ & 1 \\
\hline Shortwave infrared & $1.55-1.70$ & 1 \\
\hline Mid infrared & $3.80-4.00$ & 4 \\
\hline Water vapor & $6.50-7.10$ & 8 \\
\hline Thermal infrared 1 & $10.20-11.30$ & 4 \\
\hline Thermal infrared 2 & $11.50-12.50$ & 4 \\
\hline
\end{tabular}

Table 1: Channels of INSAT-3D Imager. Channels used in AOD algorithm are highlighted in red color.

\subsection{MODIS data}

AOD at $0.55 \mu \mathrm{m}$ and Angstrom Exponent $(0.47 / 0.66 \mu \mathrm{m}$ and $0.55 / 0.865 \mu \mathrm{m}$ ) derived from satellite data of MODIS onboard AQUA downloaded from http://gdata1.sci.gsfc.nasa.gov/daacbin is used in present study. These level 3 atmospheric products are daily available at $1^{\circ} \times 1^{\circ}$ spatial resolution in Hierarchical Data Format (HDF).

\subsection{Sun-photometer derived AOD data}

In present study AOD data (Level 1.5) from 9 AERONET sites (inland sites: Karachi, Lahore, Jaipur, Gandhi College, Dhaka_University, Kathmandu, Pokhara, Kanpur and oceanic sites: MCO-Hanimaadhoo) downloaded from http://aeronet.gsfc.nasa.gov/ is used for INSAT-3D AOD product validation over Indian subcontinent and Indian Ocean region. AOD data from one handheld MICROTOPS-II sunphotometer at SAC (ISRO), Ahmedabad is also used in present study. Locations of all sun-photometers are shown in figure 1.

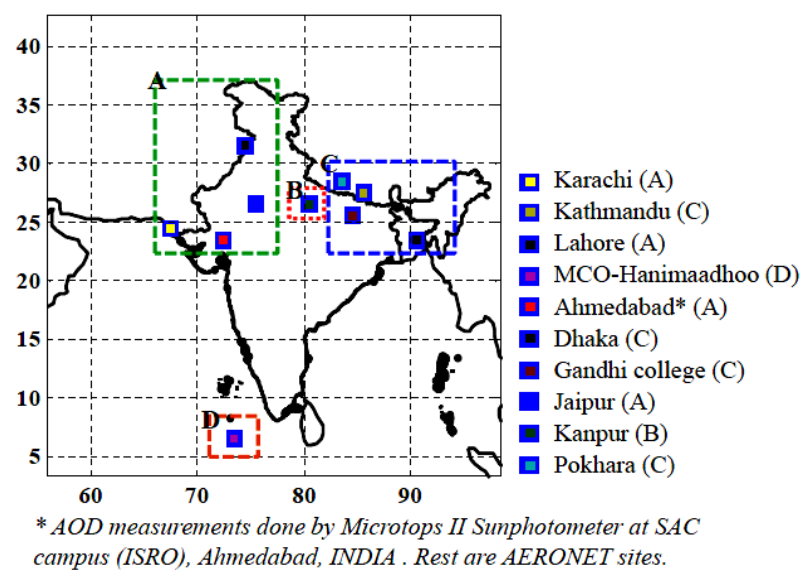

Figure1: Shows the location of 10 sites at which the AOD measured by sun-photometer is compared with AOD retrieved from INSAT-3D during the months of January, February and March 2014.

\section{THEORETICAL BASIS OF AOD RETRIEVAL ALGORITHM}

AOD retrieval algorithms based on clear sky composite method (Knapp et al., 2002; Wang et al., 2003; Yoon et al., 2007) involves estimation of surface reflectance in visible band over a period previous $\sim 30$ days. This may lead to the errors in AOD retrieval due to the sensitivity of visible channel signal with respect to factors like clouds, aerosols and surface properties. Apparent reflectance in visible and MIR channels, for different values of target pixel reflectance (surface reflectance), value of $\mathrm{AOD}$ at $0.55 \mu \mathrm{m}$ and for different aerosol models is simulated using $6 \mathrm{~S}$ radiative transfer code.The simulated results are shown in figure 2. Figure 2 (a) shows the variation of apparent reflectance in visible channel with respect to the surface reflectance for different aerosol models. Here, AOD value equal to 0.5 at $0.55 \mu \mathrm{m}$ is considered for simulation. It is clear from figure 2 (a) that apparent reflectance in visible channel at satellite level is highly sensitive to the presence of aerosols irrespective of the aerosol model considered. On the other hand from figure 2 (b) it is clear that apparent reflectance in MIR channel at satellite level is insensitive to the presence of aerosols irrespective of the aerosol model considered. Figure 2 (c) shows that for a given value of surface reflectance at 0.55 $\mu \mathrm{m}$ (here 0.1 is considered) the apparent reflectance in visible channel at satellite level is highly sensitive to AOD value, while in MIR channel is insensitive to AOD values as compared to visible channel. This relative insensitivity of MIR channel to the presence of aerosols in atmosphere can be utilized for correction of surface reflectance in existing single visible band based clear sky composite method (Knapp et al., 2002; Wang et al., 2003; Yoon et al., 2007) for AOD retrievals. Using 6S RTS, modeled top of the atmosphere apparent reflectance in MIR band is compared with respect to surface reflectance in visible band for different illumination and view geometry (figure 3).In figure 3 the dashed line represents the slope of linear regression and vertical bars show the variation of modeled results with respect to different geometrical conditions. 

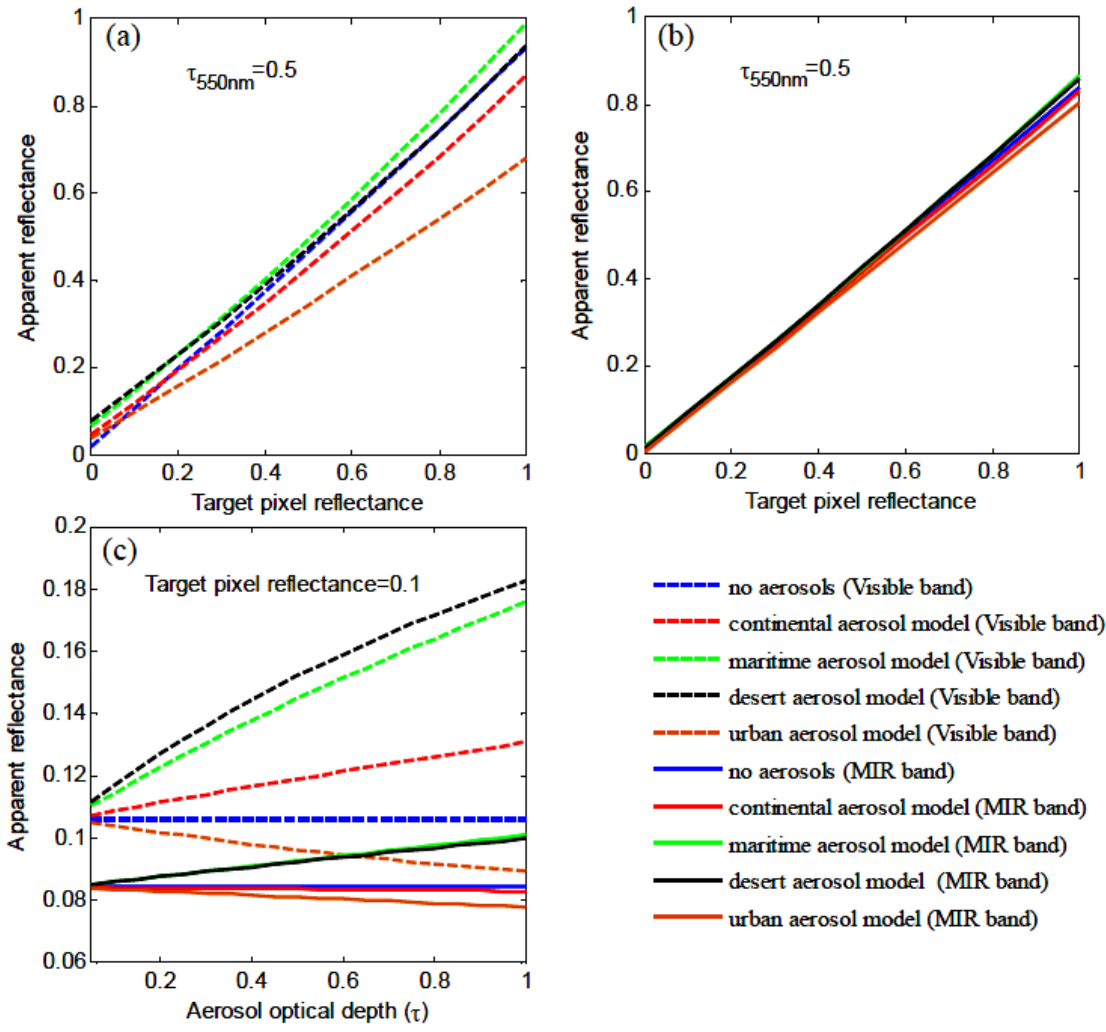

Figure 2: Shows modeled results obtained by 6S radiative transfer simulation for INSAT-3D visible and mid-infrared bands incorporated with their spectral response function. Plots (a) and (b) shows the variation of modeled apparent reflectance in visible and in mid-infrared band with respect to the target pixel reflectance for clear atmosphere and for different aerosol models with AOD value equal to 0.5 at $0.55 \mu \mathrm{m}$. Plot (c) shows the variation of modeled apparent reflectance in visible and in mid-infrared band with respect to AOD values for clear atmosphere and for different aerosol models with target pixel reflectance value equal to 0.1 at 0.55 $\mu \mathrm{m}$.

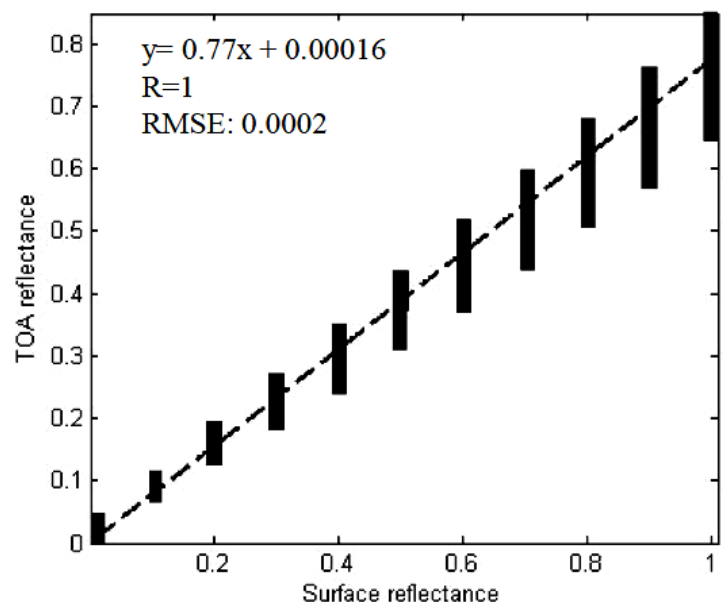

Figure 3: Comparison of modelled top of the atmosphere apparent reflectance in mid-infrared band with respect to surface reflectance in visible band for INSAT 3D using 6S radiative transfer simulation incorporated with spectral response function for INSAT 3D visible and mid-infrared band. The dashed lines represent the slopes of linear regression and vertical bars shows the variation of modelled results with respect to different geometrical conditions. The geometrical conditions for simulation are from $0^{\circ}$ to $75^{\circ}$ (interval $5^{\circ}$ ) for sun zenith angles, from $0^{\circ}$ to $75^{\circ}$ (interval $5^{\circ}$ ) for satellite zenith angles and $0^{\circ}$ to $180^{\circ}$ (interval $10^{\circ}$ ) for relative azimuth angles.

\section{DESCRIPTION OF AOD RETRIEVAL ALGORITHM FOR INSAT-3D}

INSAT-3D AOD retrieval mainly uses the visible and MIR channel to extract aerosol information. Figure 4 shows the complete flowchart of the algorithm. This algorithm compiles of three parts: (A), (B) and (C). The right one (A) is the main AOD retrieval part, the central one (B) focuses on surface reflectance retrieval, while left one (C) is for correction of surface reflectance through MIR channel. In part (A), INSAT-3D visible band radiance data is converted to top of the atmosphere (TOA) reflectance $\rho_{T O A}^{\prime}$. At first stage $\rho_{T O A}^{\prime}$ is atmospherically corrected for ozone absorption and for Rayleigh scattering using LUTs constructed for different geometrical conditions through 6S RTS. The geometrical conditions for RTS are from $0^{\circ}$ to $75^{\circ}$ (interval $5^{\circ}$ ) for sun zenith angles $\theta_{\mathrm{s}}$, from $0^{\circ}$ to $75^{\circ}$ (interval $5^{\circ}$ ) for satellite zenith angles $\theta_{\mathrm{v}}$ and $0^{\circ}$ to $180^{\circ}$ (interval $10^{\circ}$ ) for relative azimuth angles $\Delta \phi$. This gives us with semi-surface reflectance $\rho_{s}^{\prime}$. In next step, clear sky composite $\left(\rho_{s}\right)$ image is generated by computing $2^{\text {nd }}$ minima of $\rho_{s}^{\prime}$ for each pixel over a period of previous 30 days with the assumptions that there is at least one clear-sky condition and that surface conditions do not change during this period. Now coming to part (C) in which MIR reflectance is estimated using INSAT-3D Imager data. This is then corrected for thermal component using Planck's model and brightness temperature in thermal infra-red (TIR1) channel $(10.8 \mu \mathrm{m})$. For correcting the estimated surface reflectance $\rho_{s}$ obtained by clear sky composite method, LUTs 
C

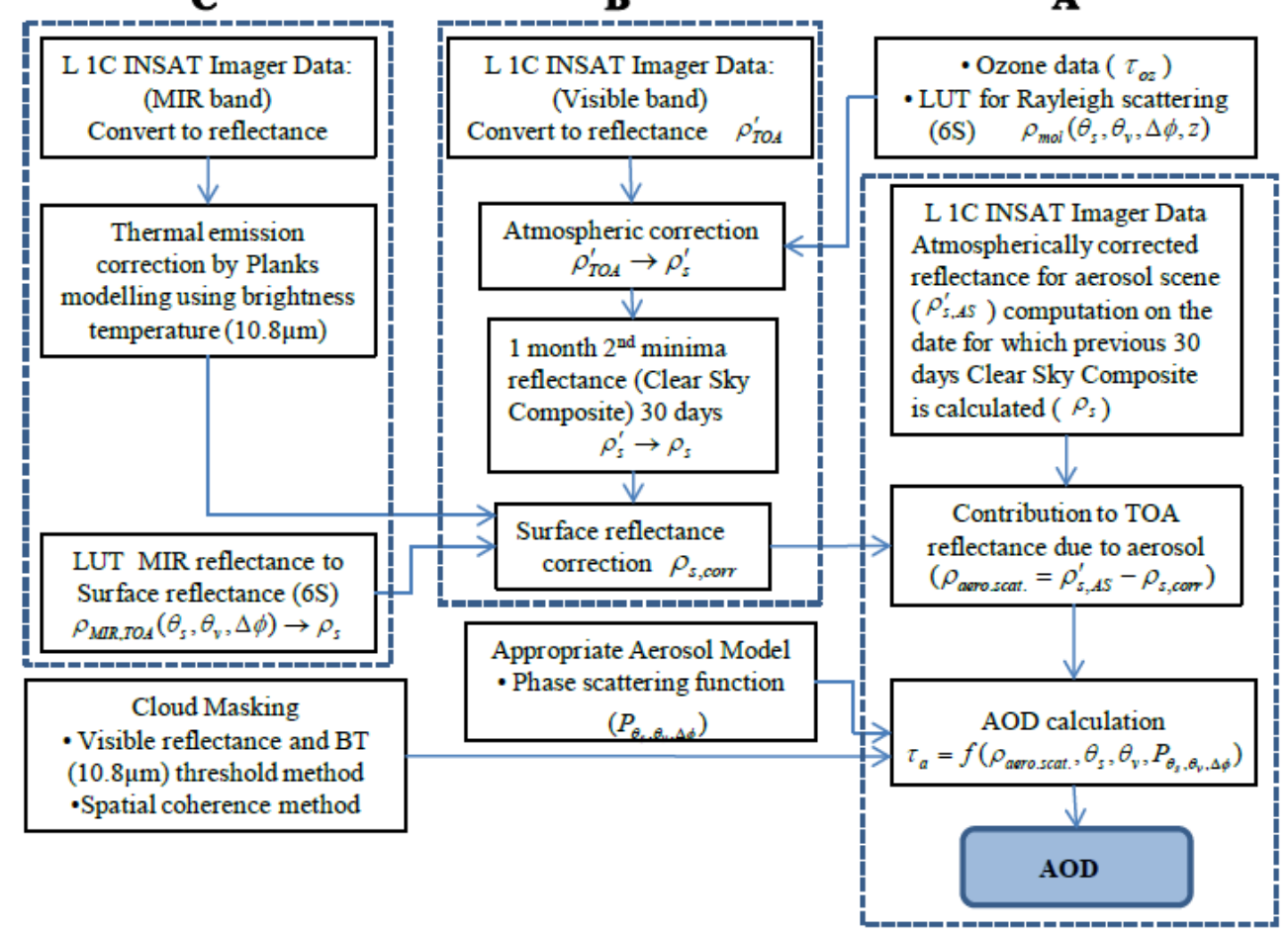

Figure 4: Flowchart for AOD retrieval algorithm.

are constructed by 6S RTS for top of the atmosphere apparent reflectance in visible and MIR band of INSAT-3D with respect to different surface reflectance at $0.55 \mu \mathrm{m}$ and for different illumination and view geometries. This gives us the corrected surface reflectance $\rho_{s, \text { corr }}$ in visible band. In order to compute contribution of aerosols in the TOA reflectance, estimated surface reflectance is subtracted from Rayleigh corrected TOA reflectance. After estimating aerosol contribution AOD is computed using appropriate aerosol model. As AOD should be retrieved only for cloudless pixels, the cloudy pixels are masked out by defining the threshold limits for reflectance in visible band and brightness temperature in TIR1 and by using spatial coherence method. The optical properties of the aerosols are one of the important sources of errors other than errors in characterizing the surface reflectance in computing AODs from geostationary platform (e.g. Knapp et al. 2002).

\section{RESULTS}

The INSAT-3D derived AOD $\left(\tau_{\mathrm{I}}\right)$ values are compared with sun-photometer AOD values $\left(\tau_{\mathrm{A}}\right)$ (at 0800 UTC). Figure 1 shows the location of 10 sites (9 AERONET sites and 1 handheld sun-photometer site at SAC, Ahmedabad) at which the AOD measured by sun-photometers are compared with INSAT-3D derived AOD during the months of January, February and March (JFM), 2014. Extensive validation made during JFM 2014 encompasses 215 co-located $\tau_{\mathrm{I}}$ and $\tau_{\mathrm{A}}$ in space, and scatter plot for which is shown in figure 5. INSAT$3 \mathrm{D}$ aerosol retrievals i.e. $\tau_{\mathrm{I}}$, are found within the retrieval errors of $\tau_{\mathrm{I}}= \pm 0.07 \pm 0.15 \tau_{\mathrm{A}}$ with linear correlation coefficient $(\mathrm{R})$ of 0.90 and RMSE equal to 0.06 .

AODs are estimated from INSAT-3D data on the daily basis during JFM 2014. AOD product of MODIS is available at 0.55 $\mu \mathrm{m}$ and $1^{\circ}$ spatial resolution. In order to compare this product with INSAT-3D derived AODs, Angstrom Exponent product of MODIS is utilized to extrapolate MODIS AOD $\left(\tau_{\mathrm{M}}\right)$ values to
$0.65 \mu \mathrm{m}$ wavelength. Monthly composites for the month of January, February and March 2014 are prepared for AOD comparison. Figure 6 shows qualitative comparison of monthly (January, 2014) composite AOD retrieved from INSAT-3D Imager data and Aqua/MODIS at $0.65 \mu \mathrm{m}$. Figure 7 shows quantitative comparison of monthly composite AOD values retrieved from INSAT-3D data (0800 UTC) and Aqua/MODIS at $0.65 \mu \mathrm{m}$. Scatter plots in figure 7 shows comparison of INSAT-3D (y-axis) and MODIS (x-axis) derived AOD values. Linear correlation coefficient (R) for the months of January, February and March 2014 is equal to $0.87,0.81$ and 0.76 , respectively.

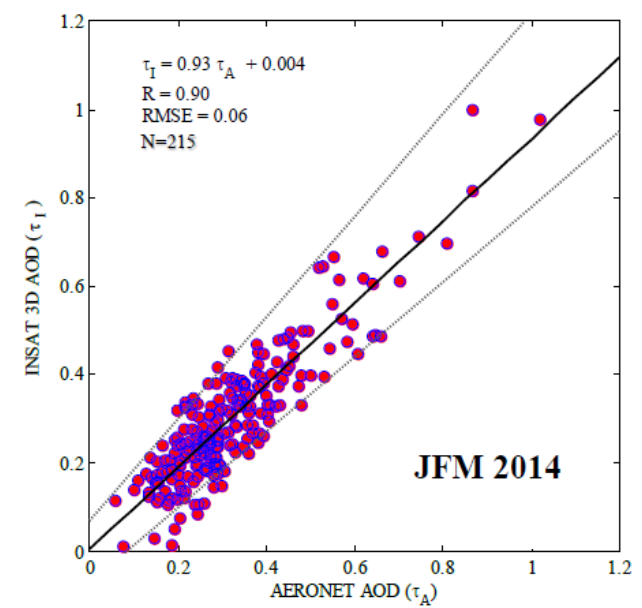

Figure 5: Comparison of INSAT-3D and AERONET derived AOD at $0.65 \mu \mathrm{m}$ wavelength, encompassing 215 points from 9 AERONET sites and 1 handheld sun-photometer at SAC (ISRO) Ahmedabad for the months of January, February and March, 2014. The solid lines represent slope of linear regression and the dot lines the retrieval errors of of $\tau_{\mathrm{I}}= \pm 0.07 \pm 0.15 \tau_{\mathrm{A}}$. 

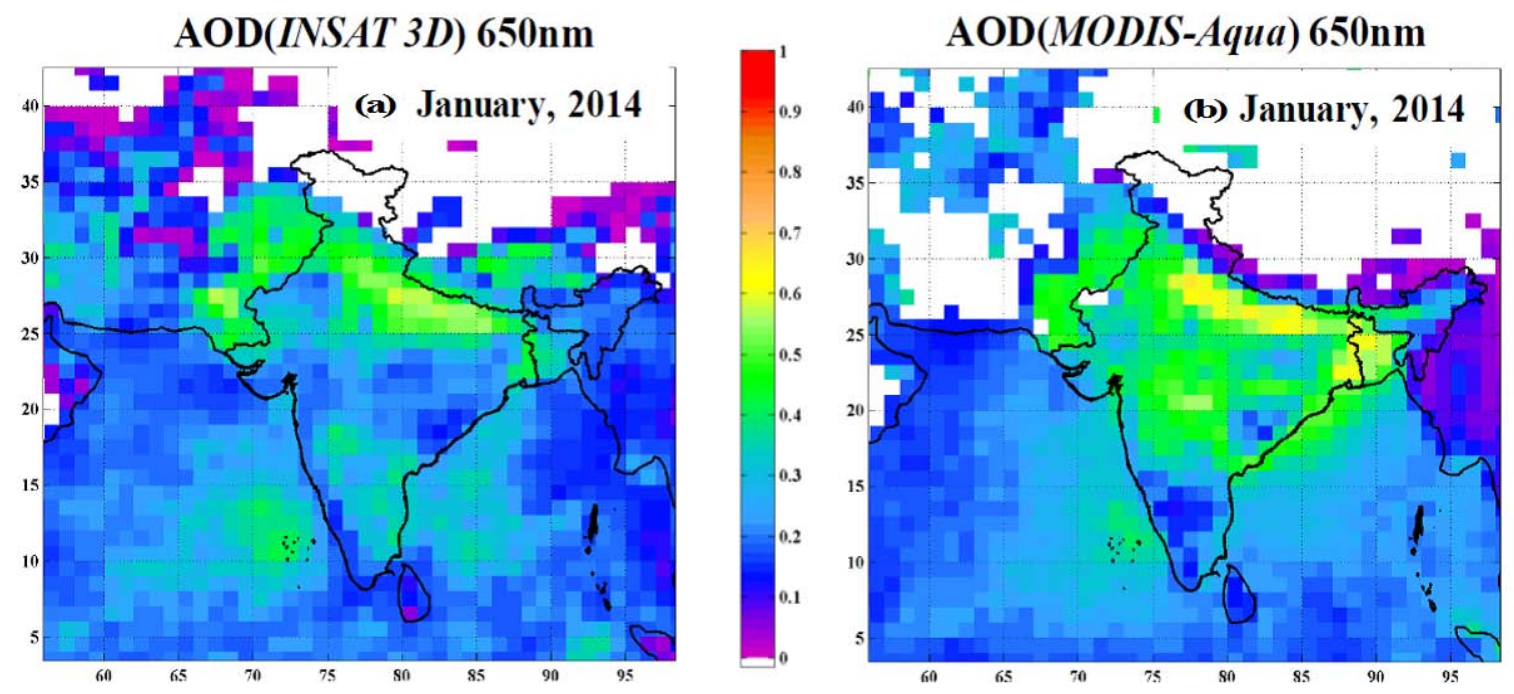

Figure 6: Qualitative comparison of monthly composite AOD retrieved from INSAT-3D Imager data and MODIS-aqua at $1^{\circ}$ resolution and at wavelength of $0.65 \mu \mathrm{m}$. (a) shows monthly composite AOD images retrieved from INSAT-3D Imager data for the month of January, 2014 (b) shows monthly composite AOD images retrieved from MODIS-aqua (http://gdata1.sci.gsfc.nasa.gov/daac-bin) for the month of January, 2014.
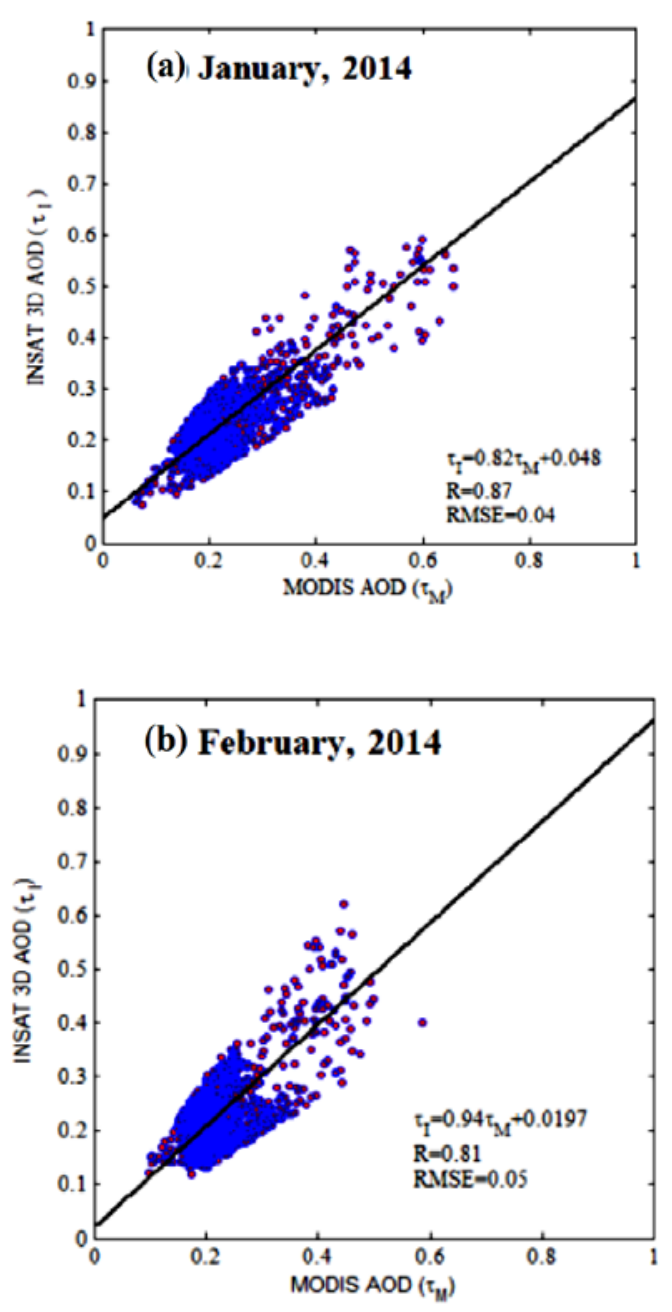

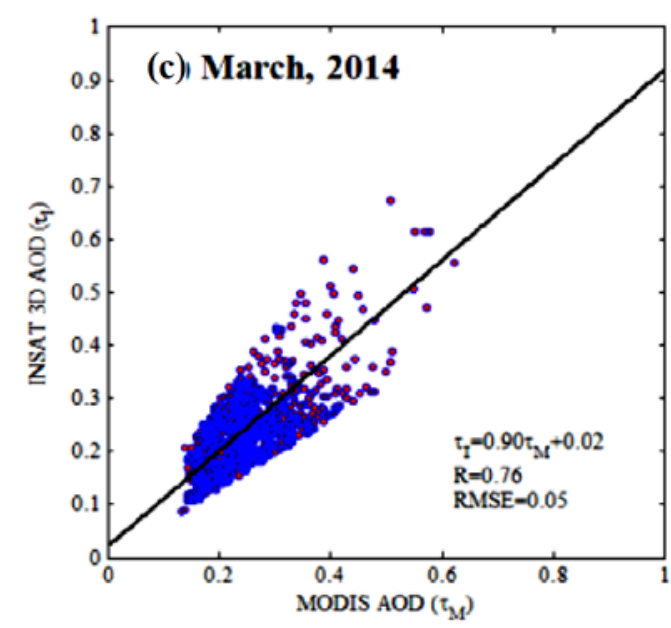

Figure 7: Quantitative comparison of monthly composite AODs retrieved from INSAT-3D Imager data (8:00 UTC) and MODIS at $0.65 \mu \mathrm{m}$ and $1^{\circ}$ resolution. Scatter plot (a), (b) and (c) shows comparison of INSAT and MODIS derived AOD values for January, February and March, 2014, encompassing 1165, 1052 and 900 pixels, respectively. Solid lines in the plots represent the slopes of linear regression.

\section{DISCUSSION AND CONCLUSION}

In the previous section it is observed that the AOD pattern obtained from INSAT-3D and MODIS matches fairly to each other throughout the Indian landmass and oceanic region. Both INSAT-3D and MODIS derived monthly composite AOD images shows high aerosol concentration over north Indian landmass (especially in Indo-Gangetic region) during the study period. The results presented in this paper shows good agreement between INSAT 3D derived AODs and sunphotometer AODs. In the regions where sun-photometer data is available INSAT-3D aerosol retrievals i.e. $\tau_{\mathrm{I}}$, are found within the retrieval errors of $\tau_{\mathrm{I}}= \pm 0.07 \pm 0.15 \tau_{\mathrm{A}}$ with linear correlation 
coefficient (R) of 0.90 and RMSE equal to 0.06 . These uncertainties may be due to various factors like cloud residuals, higher AOD values at coastal region because of water contaminated pixels. Another important source of error is due to uncertainty in surface reflectance estimation using MIR channel. As can be seen from figure 2(b), there is high variation in MIR signal at satellite level for high target pixel reflectance. For this reason the uncertainty in estimated surface reflectance may become appreciable over bright surfaces (desert, snow/ice covers etc.). Other than this, uncertainty in appropriate aerosol model selection may also act as one source of error in INSAT3D derived AOD. In conclusion MIR channel assisted AOD retrieval algorithm utilizing GEO satellite INSAT-3D/Imager data is presented. Using this algorithm the performance of INSAT-3D retrieved AODs during the period of January, February and March 2014 is analyzed with respect to AODs derived from sun-photometers located at various locations in the given study region and from MODIS. On an average the linear correlation coefficient (R) equal to 0.81 and 0.90 is obtained with respect to MODIS and sun-photometer derived AODs at $0.65 \mu \mathrm{m}$, respectively. INSAT-3D aerosol retrievals i.e. $\tau_{\mathrm{I}}$, are found within the retrieval errors of $\tau_{\mathrm{I}}= \pm 0.07 \pm 0.15 \tau_{\mathrm{A}}$ with respect to sun-photometer derived AODs. Nonetheless, the agreement between the two AODs (i.e., $\tau_{\mathrm{I}}$ and $\tau_{\mathrm{A}}$ ) is significant and suggests the possibility of using INSAT-3D aerosol retrievals to augment the low temporal resolution aerosol retrievals from LEO satellites.

\section{REFERENCES}

Diner, D.J., Abdou, W.A., Ackerman, T.P., Crean, K., Gordon, H.R., Kahn, R.A., Martonchik, J.V., Paradise, S.R., Pinty, B., Versteraete, M.M., Wang, M. and West, R.A. (1996). Multiangle imaging spectro-radiometer: level 2 aerosol retrieval algorithm. EOS ATBD-JPL D-11400, Rev. B, 81.

Higurashi, A. and Nakajima, T. (1999). Development of a twochannel aerosol retrieval algorithm on a global scale using NOAA AVHRR. Journal of the Atmospheric Sciences, 56, pp. 924-941.

Higurashi, A. and Nakajima, T. (2002). Detection of aerosol types over the East China Sea near Japan from four-channel satellite data. Geophysical Research Letters, 29, pp. 17-1-17-4.

Ignatov, A. and Stowe, L. (2000). The physical basis, premises, and self consistency checks of aerosol retrievals from TRMM VIRS. Journal of Applied Meteorology, 39, pp. 2259-2277.

Kaufman, Y.J., Tanre, D., Remer, L.A., Vermote, E.F., Chu, A. and Holben, B.N. (1997). Operational remote sensing of tropospheric aerosol over land from EOS moderate resolution imaging spectro-radiometer. Journal of Geophysical Research, 102, pp. 17 051-17 068.

Kaufman, Y.J. and Remer, L.A. (1994). Detection of forests using mid-IR reflectance: an application for aerosol studies. IEEE Transactions on Geoscience and Remote Sensing, 32, pp. 672-683.

Kaufman, Y. J., et al. (2000). Detection of dust over the desert by EOS-MODIS, IEEE Trans. on Geos. and Remote Sens., 38, 525- 531.

Kim, J., Lee, J., Lee, H.C., Higurashi, A., Takemura, T. and Song, C.H. (2007). Consistency of the aerosol type classification from satellite remote sensing during the ABC
EAREX campaign. Journal of Geophysical Research, 112, D22S33.

Kim, J., Yoon, J. -M, Ahn, M.H., Sohn, B.J. and Lim, H.S. (2008). Retrieving aerosol optical depth using visible and midIR channels from geostationary satellite MTSAT-1R. International Journal of Remote Sensing, 29:21, 6181-6192.

Knapp, K.R., Von Der Haar, T.H. and Kaufman, Y.J. (2002). AOD retrieval from GOES-8: uncertainty study and retrieval validation over South America. Journal of Geophysical Research, 107, pp. 4055.

Tanre, D., et al. (1997). Remote sensing of aerosol over oceans from EOS-MODIS, J. Geophys. Res., 102, 16,971- 16,988

Vermote, E.F., Tanre' , D., Deuze, J.L., Herman, M. and Morcrette, J.J. (1997). Second simulation of the satellite signal in the solar spectrum, 6S: an overview. IEEE Transactions on Geoscience and Remote Sensing, 35, pp. 675-686.

Wang, J., Christopher, S.A., Brechtel, F., Kim, J., Schmid, B., Redemann, J., Russell, P.B., Quinn, P. and Holben, B.N. (2003). Geostationary satellite retrievals of aerosol optical thickness during ACE-Asia. Journal of Geophysical Research, 108, pp. 1-14.

Yoon, J. -M., Kim, J, Lee, J, Cho, H.K., Sohn, B.J., and Ahn, M.H.. (2007). Retrived of aerosol optical depth over east asia from a geostationary satellite, MTSAT-1R, Journal of the Korean metrological society, 43, 133-142. 